\title{
Correction to: Core Rehabilitation Outcome Set for Single Sided Deafness (CROSSSD) study: protocol for an international consensus on outcome measures for single sided deafness interventions using a modified Delphi survey
}

\author{
Roulla Katiri 1,2,3, Deborah A. Hall 1,3,4, Nora Buggy ${ }^{1}$, Nicholas Hogan ${ }^{1}$, Adele Horobin ${ }^{1,5}$, Paul van de Heyning ${ }^{6,7}$, \\ Jill B. Firszt ${ }^{8}$, lain A. Bruce ${ }^{9,10}$ and Pádraig T. Kitterick ${ }^{1,3,5^{*}}$
}

Correction to: Trials

https://doi.org/10.1186/s13063-020-4094-9

Following the publication of our article [1], the authors have notified us of a typo in the third bullet point of the Consensus Criteria section.

- Original phrase:

"For outcomes in which less than $50 \%$ of the participants in all stakeholder groups scored 1-7 on the round 2 analysis (...)"

- Corrected phrase:

The original article can be found online at https://doi.org/10.1186/s13063 020-4094-9

*Correspondence: padraig.kitterick@nottingham.ac.uk

${ }^{1}$ National Institute for Health Research (NIHR) Nottingham Biomedical

Research Centre (BRC), Ropewalk House, 113 The Ropewalk, Nottingham NG1 5DU, UK

${ }^{3}$ Hearing Sciences, Division of Clinical Neuroscience, School of Medicine, University of Nottingham, Nottingham NG7 2UH, UK

Full list of author information is available at the end of the article
"For outcomes in which less than $50 \%$ of the participants in all stakeholder groups scored 7-9 on the round 2 analysis (...)"

Also, the link included in the Funding section, right after "the 15th International Conference on Cochlear Implants and Other Implantable Auditory Technology" was removed.

The original article has been corrected.

\begin{abstract}
Author details
${ }^{1}$ National Institute for Health Research (NIHR) Nottingham Biomedical Research Centre (BRC), Ropewalk House, 113 The Ropewalk, Nottingham NG1 5DU, UK. ${ }^{2}$ Department of Audiology, Mater Misericordiae University Hospital, Dublin D07 R2WY, Ireland. ${ }^{3}$ Hearing Sciences, Division of Clinical Neuroscience, School of Medicine, University of Nottingham, Nottingham NG7 2UH, UK. ${ }^{4}$ University of Nottingham Malaysia, Jalan Broga, 43500 Semenyih, Selangor Darul Ehsan, Malaysia. ${ }^{5}$ Nottingham University Hospitals NHS Trust, Queen's Medical Centre, Derby Road, Nottingham NG7 2UH, UK. ${ }^{6}$ Department of Otorhinolaryngology, Head and Neck Surgery, Antwerp University Hospital, Antwerp, Belgium. ${ }^{7}$ Experimental Laboratory of Translational Neurosciences and Dento-Otolaryngology, Faculty of Medicine and Health Sciences, University of Antwerp, Antwerp, Belgium. ${ }^{8}$ School of Medicine, Washington University in St. Louis, St. Louis, Missouri, USA. ${ }^{9}$ Manchester University Hospitals NHS Foundation Trust, Manchester Academic Health Science Centre, Oxford Road, Manchester M13 9WL, UK.

${ }^{10}$ Division of Infection, Immunity and Respiratory Medicine, Faculty of
\end{abstract}

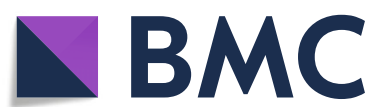

c) The Author(s) 2020 Open Access This article is licensed under a Creative Commons Attribution 4.0 International License, which permits use, sharing, adaptation, distribution and reproduction in any medium or format, as long as you give appropriate credit to the original author(s) and the source, provide a link to the Creative Commons licence, and indicate if changes were made. The images or other third party material in this article are included in the article's Creative Commons licence, unless indicated otherwise in a credit line to the material. If material is not included in the article's Creative Commons licence and your intended use is not permitted by statutory regulation or exceeds the permitted use, you will need to obtain permission directly from the copyright holder. To view a copy of this licence, visit http://creativecommons.org/licenses/by/4.0/ The Creative Commons Public Domain Dedication waiver (http://creativecommons.org/publicdomain/zero/1.0/) applies to the data made available in this article, unless otherwise stated in a credit line to the data. 
Biology, Medicine and Health University of Manchester, Oxford Road,

Manchester M13 9PL, UK.

Published online: 17 March 2020

\section{Reference}

1. Katiri, et al. Core Rehabilitation Outcome Set for Single Sided Deafness (CROSSSD) study: protocol for an international consensus on outcome measures for single sided deafness interventions using a modified Delphi survey. Trials. 2020;21:238. https://doi.org/10.1186/s13063-020-4094-9. 